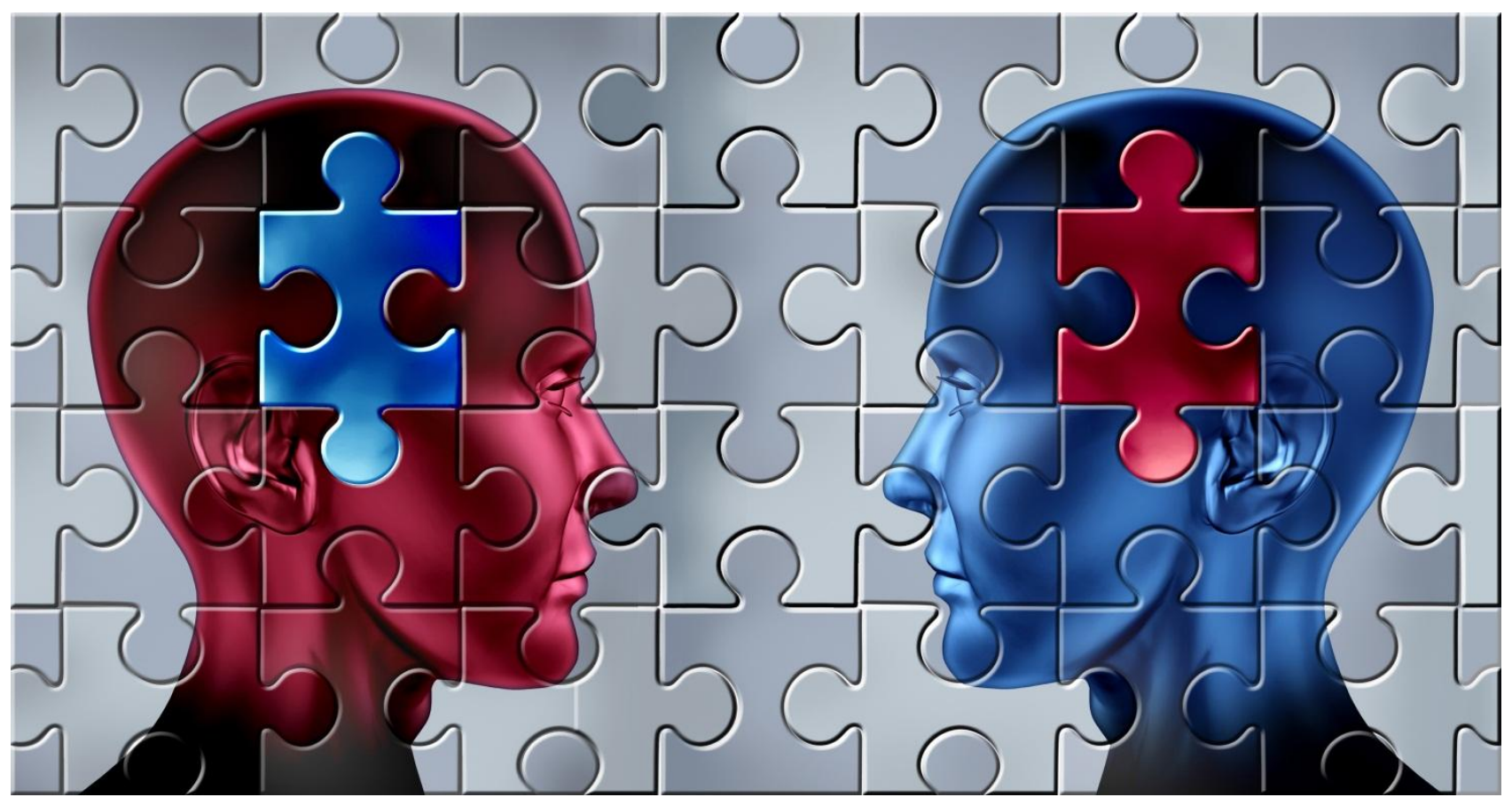

Exchanges: the Warwick Research Journal

Volume 2 (1), October 2014

http:/ / exchanges.warwick.ac.uk

Realising the Pedagogical Potential of Multilingual Pre-service Primary Teachers

Dr Jacqueline Coleman 


\title{
Realising the Pedagogical Potential of Multilingual Pre-service Primary Teachers
}

\author{
Dr Jacqueline Coleman (Australian Catholic University)
}

\begin{abstract}
This paper reports on a small, qualitative study undertaken by an early career researcher in an Australian university into the meanings which multilingual and bilingual pre-service teachers attach to their linguistic 'funds of knowledge' (Moll, Amanti, Neff and Gonzalez, 1992) in relation to their university studies, and to their emerging identities as teachers. Current pedagogical best practice in Australia indicates that drawing on students' existing funds of knowledge in teaching and learning results in increased intellectual quality, such as higher order thinking skills, and higher academic outcomes. However, the participants in this study did not conceptualise their linguistic abilities as having any value in relation to their higher education. They also appeared to tacitly accept reported institutional and pedagogical practices which marginalised these abilities both as tools for learning and for informing their developing identities as teachers. On the basis of these findings, broad preliminary recommendations are made as to how the learning experiences of bilingual and multilingual pre-service primary teachers, and of their monolingual peers, may be improved at this university. The study's findings point to the need for a largerscale research study into this under-investigated aspect of pre-service teacher education in Australia.
\end{abstract}

\section{Keywords: Multilingualism; English as an Additional Language; teacher education; pedagogy; knowledge base for teaching; teacher roles}

\section{Introduction}

Australia has a highly ethnically diverse population: $27 \%$ of its people are overseas-born and 19\% speak a non-English language at home (Australian Bureau of Statistics [ABS], 2013). Despite this reality, there has never been any systemic bilingual education (in which the curriculum is delivered two languages) in Australia (Gibbons, 1997). Nonetheless, the nation's multiculturalism and multilingualism are recognised in 
government policy, and indeed, Australia has a wide-ranging National Policy on Languages (Lo Bianco, 1987). This recognition has not translated into the use of nonEnglish languages outside personal domains, nor into any large-scale public events that interrogate the limited usage domains of non-English languages, such as 2013's groundbreaking Festival of Languages (http://www.theguardian.com/language-festival) in Britain, which highlighted this issue publically.

Australia has no official language, but is effectively a monolingual English-speaking country in all public domains and is marked by a 'persistent monolingual mindset' (Clyne, 2005: XI). Reflective of this context and of international trends in Englishspeaking countries, such as Britain (Safford and Kelly, 2010), Australia's teaching force is overwhelmingly of English-speaking background (Allard, 2006). However, Australia's increasing population diversity is mirrored in schools and in pre-service teacher cohorts. For example, in 2012, 15\% of all domestic students in Australian universities regularly spoke a non-English language at home (Australian Government, DIICCSRTE, 2013).

In this article, I report on a small study I am conducting at an Australian university, to explore meanings that bilingual and multilingual pre-service primary teachers attach to their linguistic ability in relation to their teacher preparation course, and to their emerging teacher identities. The study also seeks to identify preliminary implications of students' meanings for improving pedagogical practices at the Australian Catholic University (ACU). I begin with an overview of the pedagogies espoused in school level educational policy in Australia, before briefly reviewing the research base underlying them. I then contrast this strong school level policy to that of higher education, where an increasingly diverse cohort of students is enrolled.

\section{Funds of knowledge, policy and school education}

Intellectual quality is a strong focus of Australian educational policy. One means of improving intellectual quality is by linking students' outside classroom knowledge with pedagogies encouraging the use of higher order thinking skills. Such connection is pivotal to 'productive' pedagogies (Lingard, et al., 2001) in which 'teachers link the work of their students to personal, social and cultural contexts outside of the classroom' 
(NSWDET, 2006: 7) as a means of increasing academic outcomes. In Australia, outside classroom knowledge is understood to include 'beliefs, languages, practices and ways of knowing' (Amosa and Ladwig, 2004: 1). In the United States (US), Moll, Amanti, Neff and Gonzalez (1992: 133) identified a variety of knowledge of diverse students not routinely recognised in schools. Using the term 'funds of knowledge' to identify and value these 'historically accumulated and culturally developed bodies of knowledge and skills essential for household or individual functioning and well-being', they argued for 'strategic' incorporation of such funds of knowledge into educational settings as a means of increasing academic outcomes for diverse students. Among students' funds of knowledge are their diverse language skills. The issue of classroom use of students' language skills is particularly apposite given the increasing diversity of classrooms in pluralist societies such as the UK and Australia.

Similarly to the UK, in Australia, the majority of English as an Additional Language (EAL) students receive the bulk of their education in mainstream English-medium classes. Drawing on these students' linguistic ability has been recognised internationally for some time in policy as a means of realising the academic potential inherent in their 'mainstreaming'. A companion document to the Australian Curriculum: English, the EAL/D [English as an Additional Language or Dialect] Teacher Resource (Australian Curriculum and Reporting Authority [ACARA], 2011) states that teachers should actively employ EAL/D students' linguistic knowledge to 'build EAL/D students' English language learning and their curriculum content knowledge. 'It also contends that doing so 'provid[es] opportunities for deep learning and intercultural understanding for the entire class' (ACARA, 2011: 93-94). That is, diverse linguistic knowledge is framed as representing significant 'pedagogical potential' (Wallace, 2005: 82) for all students.

Using students' linguistic funds of knowledge to promote intellectual quality has a sound theoretical base in Second Language Acquisition (SLA) research. In the following section, I review some relevant findings from SLA research which illuminate why use of diverse students' linguistic knowledge promotes attainment of higher academic outcomes, before moving on to consider the use of diverse pre-service primary teachers' linguistic funds of knowledge at university. 


\section{Research supporting the use of linguistic funds of knowledge}

\section{The Bilingual Interface}

A widely accepted body of SLA research has shown that maintaining and building a child's first language (L1) is the best way to help that child to acquire an additional language (Cummins, 2000; McKay, 1999) and thus, to achieve curricular access in mainstream classes. Building students' L1s activates the potential in 'the bilingual interface' or 'the enriching and enabling knowledge, skills and experiences that ESL [English as a Second Language] learners bring to their learning at school, and to the coming together of these with their experiences at school' (McKay, 1999: 123). SLA research has also established the components of diverse students' 'enriching and enabling' language-based knowledge (Adesope, et al., 2010). Multiple studies have shown that bilinguals and multilinguals may have greater metalinguistic awareness and metacognitive skills, stronger symbolic representation and abstract reasoning skills, enhanced problem-solving skills and creative and divergent thinking, and greater cognitive flexibility than their monolingual peers (Adesope, et al., 2010; Bialystok, Craik and Luk, 2012). Surely, a formidable list of abilities to deploy for classroom learning.

\section{Identity Affirmation}

The Identity Affirmation hypothesis (Ladson-Billings, 1995) also supports the educational use of linguistic funds of knowledge. It posits that validation of the cultural identities and knowledge systems of diverse students in mainstream settings is a precondition for them to achieve academic success. Cummins and Early (2011) report the positive self-esteem and academic outcomes of affirmative pedagogies allowing diverse students to 'showcase' their linguistic ability in classrooms. Crucially, these pedagogies communicate to students that their L1 proficiency is both important and valued. They also stimulate students' 'awareness of the relationships between their home language (L1) and the school language (L2) [and] increase their awareness of the specialised language of school subjects' (Cummins and Early, 2011: 3). In other words, they develop students' meta-linguistic and meta-cognitive skills. 'Showcasing' L1 abilities affirms identities and facilitates students' participation in experiences providing 
access into curricular content in the dominant language. For this to happen in classrooms, universities must produce highly skilled teachers 'whose starting point is the learners' identities...who treat the students' lives as primary resources for learning' (Miller, 2009: 178). Given that pedagogical best practice links students' identities to new knowledge and skills (Lingard et al., 2001), understanding the meanings that students attach to their linguistic skills can potentially inform the improvement of pedagogical practices with linguistically diverse university students.

The next section considers current use of the linguistic funds of knowledge specifically of pre-service primary teachers in university courses internationally.

\section{Linguistic funds of knowledge and teacher education programmes}

As discussed earlier, at least at policy level, there is recognition that increasing diversity in classrooms requires implementation of pedagogies building on students' existing knowledge. However, a concurrent increase in diversity in pre-service teacher cohorts in universities worldwide appears not to have resulted in similar recognition and pedagogical changes to facilitate deployment of students' linguistic skills in their learning (Safford and Kelly, 2010). Consequently, the identities of linguistically diverse pre-service primary teachers are generally not being affirmed as tools for learning experiences of intellectual quality, nor as important constituents of their evolving identity as teachers (Safford and Kelly, 2010). In a study of UK diverse pre-service primary teachers, Safford and Kelly found that institutional practices 'position linguistic and minority ethnic student-trainees in ways which present particular barriers to their professional development and limit their opportunities to call upon their funds of knowledge' (2010: 402). Arguably, institutional practices at university level which deny pre-service primary teachers access to their full range of learning resources, also deny monolingual pre-service primary teachers access to the significant pedagogical potential that their multilingual peers represent.

\section{The study}

This study developed in the context sketched in previous sections. While Australian universities collect data about student linguistic diversity during enrolment, it is not 
routinely passed on to teaching staff. Consequently, the linguistic diversity of their students may be invisible to staff. The aim of this study is to follow a group of 16 bilingual and multilingual pre-service primary teachers enrolled in a teaching degree in a small Australian university, throughout their undergraduate study. (This article reports on the first 18 months of the study.) The participating students self-identified as bilingual or multilingual during enrolment and were subsequently invited by email to participate in the study.

\section{Research Design}

According to Carter and Doyle, 'Narrative and life history' are located 'at the centre of teaching practice, the study of teachers and the teacher education process' (1996: 120). Consequently, this study employed interpretive methodology as a means of 'gain[ing] access to the conceptual worlds of the participants' (Pacini-Ketchabaw and Armstrong de Almeida, 2006: 318) in relation to their linguistic funds of knowledge. The study can be described as 'an issue-driven case study' (Rodriguez and Hye-sun, 2011: 497), where the 'issue' is the role of students' diverse linguistic knowledge in their pre-service education and identity formation as teachers. Case study methodology provided a framework for collecting factual information and for eliciting narratives in order to facilitate creation of a thorough description of the pre-service primary teachers' 'conceptual worlds'.

\section{Data gathering strategies}

Thirty students participated in the first stage of data gathering, an online questionnaire seeking data on the nature and degree of students' bilingualism or multilingualism, such as languages spoken, mode of learning, self-assessment of level of literacy and/or oracy and usage domains (See Appendix). All 30 students were invited to participate in follow-up semi-structured interviews and 16 accepted the invitation. The languages spoken by interviewees were Lao, Punjabi, Arabic, Cantonese, Mandarin, Fujianese, Auslan (Australian Sign Language), Korean, Persian, Turkish, Japanese, Hindi, Polish, Greek, Vietnamese, Swahili, Kinyarwanda and French. 
The semi-structured interviews probed questionnaire responses and elicited students' narratives or 'topically specific stories organised around characters, setting and plot in answer to a single interview question' (Reissman, 2005: 1). While usually associated with social sciences, narrative-based research provides 'legitimate and valuable research data' in the area of teacher research because it 'can offer ways to explore the multiplicity and complexity of social identities of a learner/teacher' (Rodriguez and Hye-sun, 2011: 496). Key interview items were:

- Please tell me a little about the language/s you speak.

- Tell me about how you use your linguistic ability in classes at university.

- Does being bilingual/multilingual make you different from monolingual people?

All interviews were recorded and transcribed.

\section{Data Analysis}

Not all talk in interviews is narrative; shifts occur between factual, short answers (nonnarrative units) and narrative units and sequences in response to certain questions, or as initiated by the interviewee. Hence, data analysis focussed on both narrative and nonnarrative units and hierarchies within these, which indicated student positionalities. In analysing transcript data, an eclectic approach borrowing from both the 'family of approaches' (Reismann, 2005: 1) of narrative analysis (NA) and also from Critical Discourse Analysis (CDA) (Fairclough, 1995) was employed to derive themes. Textual, or structural analysis, common to both NA and CDA sought to reveal within the themes the positionalities and discourses the participants appeared to invest in, where discourse is understood as 'a socially accepted association among ways of using language, of thinking, feeling, believing, valuing and of acting, that can be used to identify oneself as a member of a socially meaningful group or "social network" (Gee, 1990: 143). This analysis functioned to illuminate power relationships implicit in students' narratives, which indicated indirectly their positionality in terms of meanings they attached to their linguistic funds of knowledge in the university context. Non-narrative data was coded and included in this analysis with the narrative data, to discern similarities and differences between the participants' positionalities and meanings. 
From this hybrid analysis, broad preliminary themes meriting further examination emerged: the utility of linguistic funds of knowledge at university; student receptivity to teacher education perpetuating 'English-only' multiculturalism; and English and 'homogeneity' of English-speaking university students. These themes are considered next, before a discussion of their possible implications for teaching and learning at ACU. (All names used for interviewees throughout the following section are pseudonyms.)

\section{Findings and Discussion}

The utility of linguistic funds of knowledge at university

Participants were able to articulate some understandings of their linguistic funds of knowledge, however, they generally saw no role for their L1s in their English-medium university course. All reported that their linguistic ability had never been acknowledged or employed as a learning resource for themselves or others at ACU. In other words, an important aspect of their personal identity was not being affirmed by staff (and by implication, their student peers) as an important fund of knowledge to inform their learning and developing identities as diverse teachers in a diverse nation. (It must be noted here that these claims are not verifiable as observation was not a feature of this phase of the study.)

\section{Receptivity to teacher education perpetuating 'English-only' multiculturalism}

What is striking in the data is perhaps not so much the lack of drawing on students' linguistic skills by university staff, but rather the students' apparent acceptance of the marginalisation of their linguistic knowledge at university, and its implicit corollary that English is the only valuable linguistic capital for university, and accordingly, for informing their evolving teacher identities. In this sense, students appear 'receptive' (Bourdieu, 1977) to teaching staff acting within the 'language marketplace' (Bourdieu, 1977) as mediators of linguistic correctness, that is, of English monolingualism at university. Describing their attitudes to the English-only medium of their course, students made comments such as 'I don't think it's an issue for me' (Mariam, ArabicEnglish bilingual). Indeed, Lien, a Cantonese-English bilingual described her 
bilingualism as 'not really relevant' to her university education. Students invariably situated their L1s in private domains of family and ethnic communities. One participant, Bao Yu, a Fujianese-English bilingual, represented this prevailing perspective when she said that English was 'for education' and Fujianese was for 'life'.

This general perspective of participants was similar to that reported in a UK study which found that bilingual and multilingual pre-service primary teachers experienced difficulty in conceptualising and articulating links between their linguistic funds of knowledge and their developing skills as teachers (Safford and Kelly, 2010). Safford and Kelly contended that these students 'required confidence to articulate and utilise their language knowledge in monolingual pedagogic contexts' (2010: 402). Given the descriptions of pedagogical practices at their university, it would appear almost impossible for participants in the present study to have 'confidence' to publically and explicitly express their diverse language knowledge in their pre-service teacher classes. As Aarushi, a Hindi-speaking participant said of her university education thus far, 'no one asked me what language I speak and what I am fluent at ... so ... the environment [is] not encouraging in terms of language.'

The lack of possibility for L1 use is related to another salient aspect in the data; that is, students' apparent lack of generalisation beyond their own 'micro' experiences at university. Their acceptance of the status quo indicated investment in wider, hegemonic, socially formed discourses and language ideologies. Principal among these is the 'naturalised' discourse (Fairclough, 1995) of the obviousness of English-only as the medium of all academic education, and as the sole valuable linguistic constituent of students' emerging teacher identities. Students' narratives conveyed their symbolic domination by powerful social systems, and their integration into the systems by which they are dominated (Blackledge, 2002). Participants appeared to tacitly consent to their subordination to the practices of an educational system perpetuating the English monolingualism of the socially powerful (including university staff) in multicultural Australia. They generally positioned themselves as without agency in regard to this issue. One participant commented, 'I have to go with the system [at the university]. The system will not go according to me'.

A number of participants spoke, however, of being asked by their teachers to comment during classes on their cultures' practices in relation to educational issues such as 
parent/child reading practices and school/home relations. (Being asked to act as a spokesperson for one's minority culture within a majority culture context is, of course, not unproblematic.) Nonetheless, the question of the role of languages other than English in education remained invisible in these contexts. Hence, while in some circumstances, aspects of cultural knowledge related to education were acknowledged and 'affirmed' by university teachers, students' linguistic knowledge remained marginalised. A clear correspondence emerges here between students' conceptualisations of their L1s as cultural artefacts and community resources, and university teachers' framing of students' diversity in the teaching space. The findings of this small study thus suggest that ACU's institutional practices are playing a role in perpetuating a conceptualisation of multiculturalism that concentrates on cultural artefacts and views the languages of non-majority cultures as extraneous to educational endeavour, and thus, to the accrual of valuable social and cultural capital through education. This finding is consistent with the findings of research carried out in relation to multilingual Adult English as an Additional Language teachers in Australia (Ellis, 2004).

\section{The homogeneity of English-speaking university students}

Consistent with their apparent acceptance of the invisibility of their linguistic abilities, the participants appeared also to invest in a discourse centred on the homogeneity of monolingual and multilingual English-speaking university students. As proficient English-speakers, and also consistent with the finding that they did not generalise beyond their own 'micro'situations, most participants did not view themselves as marginalised within the university space. Indeed, a number indicated a belief that in Australian universities monolingual and multilingual students are not distinct groups. The following comment from Mila, a Polish-English bilingual, exemplifies this orientation: 'We're [monolinguals and multilinguals] the same ... we all grew up in Australia, learn the same, have the same education system.' Any recognition that being bilingual or multilingual made them somehow different to their monolingual pre-service teacher peers was expressed in terms of access to experiences and perspectives afforded them by the cultural affiliation their languages encoded, rather than in terms of cognitive differences afforded by their multilingualism. 
There is obvious concordance here with the way in which multiculturalism was reportedly construed by university teachers in classes. Participants expressed reluctance to draw attention to their linguistic abilities in any sphere of their university life, which is perhaps not surprising given the reported prevailing institutional practices, which suggest a deficit perspective toward non-English languages and their speakers. Participants also tended to play down their linguistic skills in general, employing modifying language in their narratives, for example, 'speaking another language doesn't make me necessarily smarter in another field' (Kyung-Soon), and being bilingual is 'good, but not better' than being monolingual (Bao Yu).

\section{Drawing the themes together}

The preceding preliminary themes indicate that the meanings that students attach to their linguistic funds of knowledge reflect the institutional practices they report at this university, and those of the wider social discourses of which the university is a part. That is, that non-English linguistic knowledge is of no value in higher education and that English is the only natural medium for constructing academic knowledge in multilingual Australia. In effect, being multilingual has no role to play in informing students' preservice teacher identities. This suggests that the development of their identities as Australian teachers, that is, as English-speaking teachers in an English-medium education system, may to some degree, rely on suppression of their multilingual identities. The university's reported pedagogical practices deny students opportunities to use their full 'repertoire of resources' and to 'test [these] as they negotiate and build their professional identities in social and institutional contexts' (Miller, 2009: 175). The discourses in which students invest would appear to be perpetuated by the university's practices. The probable corollary of this negation of non-English abilities is that the nonEnglish linguistic funds of knowledge of their own future diverse school students are also not important learning assets, despite the research and policy base indicating the contrary.

At the same time, students' lack of personal recognition, and the university's lack of institutional recognition of these resources, also denies the great pedagogical potential that these resources represent to their English monolingual student peers who will 
inevitably teach in multilingual classrooms. The data suggest that institutional practices and students' own meanings in interaction are resulting in less than optimal educational opportunities for these students. The next section considers some preliminary implications of this analysis for improving teaching and learning at ACU and possibly other universities, and thus for producing better teachers for Australia's multilingual classrooms.

\section{Towards improved pedagogy}

There are a number of ways in which ACU may move toward maximising opportunities for multilingual students to draw on their linguistic funds of knowledge as learning and identity formation tools. They are considered below.

\section{Opportunities to disrupt the habitus of students and staff}

Habitus is strategic practice produced by socialisation in a particular sociocultural environment (Bourdieu, 1977) which is both reflected in, and perpetuated by, the circulation of powerful discourses. It is largely unconscious and because of this, durable (Bourdieu, 1977). However, Bourdieu (2002: 29) contends that while durable, habitus as 'a product of history, that is, of social experience and education ... may be changed by history, that is, by new experiences, education or training'. Consequently, while durable due to its origins in historical and political structures, teachers' habitus is also dynamic. This dynamism presents opportunities for disruption and change. The university needs to create opportunities for staff and students (multilingual and monolingual) to interrogate the assumptions underlying the non-English deficit discourse of institutional practices in which implicit English monolingual norms are rarely questioned in regard to how they may affect the educational participation and outcomes of linguistically diverse students, their identity formation (and affirmation), and their academic achievement.

The roots of these practices in wider hegemonic social processes need to be made visible and interrogated, given that they remain largely unexamined by many staff and students (as does staff's role as linguistic gate keepers). Ideally, such processes would provide opportunities for diverse students to extrapolate their own 'micro' experiences and narratives explicitly to wider 'macro' social processes and to share their narratives with 
staff and their monolingual student peers. Combined with opportunities for reflection on practice, their narratives could be powerful catalysts for change, given that students' personal narratives 'can mean something else (and more) when their voices are considered in concert and positioned as part of a larger discourse within teacher education' (Rodriguez and Hye-sun, 2011: 498). In so doing, students may be able to step beyond their passive receptivity to the invisibility of their linguistic ability at university. Simultaneously, changed pedagogical practices could begin to disrupt ACU's role as an agent of perpetuation of English-only multiculturalism in Australia. Within this process, administrative steps could be taken to position student multilingualism more visibly, such as through passing on data about student 'linguistic funds of knowledge' to staff as a matter of course.

\section{Protocols for interrogating course content}

Another long-term means of opening up the pedagogical potential of multilingual preservice primary teachers would be through the development of protocols to interrogate the positionalities, privileging and silences in relation to linguistic diversity within university subjects, and textbooks assigned for these subjects. This process may consider, for example, issues such as how orientations within subject content to the development of sensitivity to the 'otherness' of multilingual students might be replaced by academic understanding of the cognitive advantages of multilingualism.

\section{SLA research outcomes as core content}

A third possible way forward would be through the inclusion of relevant SLA research findings as core content in all pre-service teacher programmes, and the development of appropriate pedagogical models for doing this. At present at ACU, SLA outcomes are included only in elective undergraduate subjects. This, in itself, indicates the marginalised status of non-English languages, and by implication, their speakers, in this university. Explicit teaching of SLA outcomes could function on a number of levels: to raise the status of non-English languages, and by implication, their speakers; to make the implicit knowledge of bilinguals and multilinguals more explicit; and to provide 
received, expert knowledge about multilingualism not available to monolinguals through any means besides education.

\section{Limitations of the study}

There are numerous limitations to this study, including the self-selected nature of participants and their small number. In addition, students' comments about staff's practices were not verified through observation. Nonetheless, the study provides a description of a contemporary Australian university context and of how students' meanings, in intersection with reported institutional practices, act to limit these students' learning potential, and arguably, that of their monolingual peers. This description, and any validity of a generalisable nature that it might hold, potentially represent a valuable contribution to practice in other contexts, and merit further investigation.

\section{Conclusion}

This article has reported on a small study amongst bilingual and multilingual pre-service primary teachers in an Australian university. It found that students did not place value on their diverse linguistic funds of knowledge in relation to the accrual of academic knowledge at university. Students appeared to conform to reported institutional practices in the university, which rendered these funds of knowledge invisible. They lacked confidence and opportunities to draw on their linguistic skills for university learning, or to inform their emerging teacher identities. The article also considered implications of the study's results for pedagogical practices in ACU, and made recommendations for steps that could be taken to improve these including, structured opportunities to disrupt the habitus of staff and students, development of protocols for interrogating course content and teaching SLA research outcomes as core content of undergraduate programmes. 


\section{References}

Adesope, O., T. Lavin, T. Thompson, and C. Ungerleider (2010), 'A Systematic Review and Meta-Analysis of the Cognitive Correlates of Bilingualism', Review of Educational Research, 80(2), 207-245

Allard, A. (2006), "A bit of a chameleon act": A case study of one teacher's understanding of diversity', European Journal of Teacher Education, 29(3), 319340

Amosa, W. and J. Ladwig (2004), 'Examining Non-dominant Cultural Perspectives in Pedagogical Practice', Australian Association for Research in Education conference, Melbourne, 29 November-2 December, 2004

Australian Bureau of Statistics (2013), 'Cultural Diversity in Australia' http://www.abs.gov.au/ausstats/abs@.nsf/Lookup/2071.0main+features9020122013, accessed on 19 October 2013

Australian Curriculum, Assessment and Reporting Authority (2011), 'English as an additional language or dialect' Teacher resource, http://www.acara.edu.au/ accessed on 24 October 2013

Australian Government, Department of Industry, Innovation, Climate Change, Science, Research and Tertiary Education [DIICCSRTE] (2013), 'All Domestic Students by Language Spoken at Home, Type of Attendance and Gender, Full Year 2012', http://www.innovation.gov.au/highereducation/HigherEducationStatistics/Pages/O verviewOfHigherEducationStatisticsCollections.aspx, accessed on 1 November 2013

Bialystok, E., F.I.M Craik and G. Luk (2012), 'Bilingualism: Consequences for mind and brain', Trends in Cognitive Sciences 16, 240-250

Blackledge, A. (2002), 'The Discursive Construction of National Identity in Multilingual Britain', Journal of Language, Identity and Education, 1(1), 67-87

Bourdieu, P. (1977), Outline of a Theory of Practice, Cambridge, UK: Cambridge University Press.

Bourdieu, P. (2002), 'Habitus', in Hillier, J. and E. Rooksby (eds.), Habitus: A sense of place, Aldershot: Ashgate, pp. 27-37 
Carter, K. and W. Doyle (1996), 'Personal Narrative and Life History in Learning to Teach'. In J. Sikula, T. J. Buttery and E. Guyton (Eds.), Handbook of Research on Teacher Education (2nd ed.), New York: Macmillan. pp. 120-142

Clyne, M. (2005), 'The social responsibility and impact of the linguist/applied linguist in Australia', Australian Linguistic Society conference, Melbourne, September 2830,2005

Cummins, J. (2000), Language, Power and Pedagogy: Bilingual children in the crossfire, Clevedon: Multilingual Matters.

Cummins, J. and M. Early (eds.), (2011), Identity Texts: the collaborative construction of power in multilingual schools, Stoke-on-Trent, UK: Trentham.

Ellis, E. (2004), The Invisible multilingual teacher: the contribution of language background to Australian ESL teachers' Professional knowledge and beliefs, International Journal of Multilingualism, 1, 90-108.

Fairclough, N. (1995), Critical Discourse Analysis: the critical study of language, London: Longman

Gee, J. (1990), Social Linguistics and Literacies: Ideologies in Discourses, New York: Falmer

Gibbons, J. (1997), 'Australian bilingual education', in Cummins, J. and D. Corson (eds.), Encyclopaedia of Language and Education. (Vol. 5: Bilingual Education), Amsterdam: Kluwer Educational Publishers, pp.209-215

Ladson-Billings, G. (1995), 'Toward a Theory of Culturally Relevant Pedagogy', American Educational Research Journal, 32(3), 465-491

Lingard, B., J. Ladwig, M. Mills, M. Bahr, D. Chant, M. Warry, et al. (2001), The Queensland School Reform Longitudinal Study. Brisbane: Education Queensland.

Lo Bianco, J. (1987). National Policy on Languages, Canberra: Australian Government Publishing Service

McKay, P. (1999), 'The Bilingual Interface Project: The relationship between first language development and second language development as students begin the 
learning of English in the context of schooling', Queensland Journal of Educational Research, 15(1), 123-132

Miller, J. (2009), 'Teacher Identity', in Burns, J. and C. Richards (eds.), The Cambridge Guide to Second Language Teacher Education, Cambridge, UK: Cambridge University Press, pp. 172-181

Moll, L. C., C. Amanti, D. Neff, and N. Gonzalez (1992), 'Funds of Knowledge for Teaching: Using a Qualitative Approach to Connect Homes and Classrooms', Theory into Practice, 31(2), 132-141

New South Wales Department of Education and Training [NSWDET] (2006) Quality Teaching in New South Wales Public Schools. A Classroom Practice Guide. Sydney: New South Wales Department of Education and Training.

Pacini-Ketchabaw, V. and A.E. Armstrong de Almeida (2006), 'Language discourses and ideologies at the heart of early childhood education', International Journal of Bilingual Education and Bilingualism, 9(3), 310-341

Riessman, C. K. (2005), 'Narrative Analysis', in Narrative, Memory and Everyday Life, Huddersfield: University of Huddersfield, pp. 1-7

Rodriguez, T. L. and C. Hye-sun (2011), 'Eliciting critical literacy narratives of bi/multilingual teacher candidates across the U.S', Teaching and Teacher Education, 27(3), 496-594

Safford, K. and A. Kelly (2010), 'Linguistic Capital of Trainee Teachers: knowledge worth having?', Language and Education, 24(5), 401-414

Wallace, C. (2005), 'The Cultural and Linguistic Resources of Advanced Bilingual Learners in a Multilingual London School', Prospect, 2005(1), 82-94 


\section{Appendix}

\section{Initial questionnaire}

1. What was/were the first language/s you used as a child?

2. How many languages other than English do you know? Please list them here.

3. How, where and when did you learn that/ those language/s?

4. Who do you use that/ those language/s with?

5. In what situations do you use that/those languages (e.g. social, religious ceremonies, daily family communication, study)

6. Have you had any formal, ongoing instruction in that/those languages since commencing primary school? If yes, please indicate in which language/s and describe the type of instruction, place of instruction and frequency of instruction.

Name of Language

Details

7. Please name each of the languages you know below and circle the letter/s that best describes your current use.

Name of Language

a) I understand when spoken to in this language, but cannot speak it well b) I can speak it c) I can write it d) I can read it e) Other-please describe here

8. For each language choose the letter that best describes your assessment of your overall ability level. Name of Language

a) basic

b) moderate

c)strong

d) fluent

e) Other-please describe here

9. What do you consider your first, or strongest, language now? Why?

10. Do you have any comment you'd like to add about the languages you know?

Thank you very much for time and your valuable co-operation with this project. 